\title{
A Theoretical Investigation of Potential High Energy Density Compounds of Keto RDX Derivatives with $-\mathrm{NO}_{2}$ and $-\mathrm{F}$ Groups
}

\author{
RANGASWAMY MURUGESAN $^{1 *}$ and C THEIVARASU ${ }^{2}$ \\ ${ }^{1}$ Director General of Quality Assurance, Min of Defence, CQAFE, Pune-411027, India \\ ${ }^{2}$ PSG College of Technology, Coimbatore, Tamilnadu-641004. India \\ murugeshdenalai@gmail.com
}

Received 28 August 2015 / Accepted 5 October 2015

\begin{abstract}
The detailed analysis of quantum chemical study that was performed using several computational methods, including $\mathrm{B} 3 \mathrm{LYP} / 6-31 \mathrm{G}(\mathrm{d}, \mathrm{p})$ theoretical level, for series of explosive compounds designed based on the Keto-RDX (A) structure is discussed. The heat of formation (HOFs) of the keto RDX compounds were calculated via isodesmic reaction. The detonation properties were evaluated by using the Kamlet-Jacobs equations. The bond dissociation energies (BDEs) for the thermolysis initiation bond were also analyzed to investigate the thermal stability. The results show that the keto RDX derivatives have high positive HOF values, high detonation properties and meet the basic stability requirement. Additionally, a feasible synthetic route of the high energy density compound (HEDC) is also proposed via retrosynthetic analysis.
\end{abstract}

Keywords: Keto RDX, DFT, Heats of formation, Detonation properties, Bond dissociation energy.

\section{Introduction}

During the last few decades, high energy density compounds (HEDCs) have been receiving considerable attention because of their wide range of uses both in military and civilian applications ${ }^{1-4}$. To affirm precisely, from the original explosives 1,3,4,6-tetranitroglycouril (TNGU), hexahydro-1,3,5-trinitro-1,3,5-triazine (RDX) and 1,3,5,7-tetranitro-1,3,5,7tetraazacyclooctane (HMX) to the emerging explosives trans-1,4,5,8- tetranitro-1,4,5,8tetraazadecalin (TNAD) ${ }^{5}, 2,4,6,8,10,12$ - hexanitro-2,4,6,8,10,12-hexa azaisowurtzitane (CL-20) ${ }^{6}$ and cis-2,4,6,8-tetranitro- $1 \mathrm{H}, 5 \mathrm{H}-2,4,6,8$-tetraazabicyclo[3.3.0] octane (bicycle-HMX) ${ }^{7}$, are all HEDCs with high positive heats of formation (HOFs) and excellent detonation properties. There are wide variety species of HEDCs however, each has its own advantages and disadvantages. To brief, though TNGU, and keto $\mathrm{RDX}^{8}$ possess superior detonation properties, has poor stability in moisture due to the carbonyl groups at the end of the molecules. On the other hand, $\mathrm{N}$-containing cyclic and heterocyclic structures are the traditional sources of energetic materials. Based on the above mentioned reasons, a parent structure (Figure 1, B) was designed from keto RDX, 
in which the $-\mathrm{C}=\mathrm{O}$ group was replaced by the $-\mathrm{C}=\mathrm{N}-$ group. $\mathrm{C}_{3} \mathrm{H}_{5} \mathrm{~N}_{7} \mathrm{O}_{6}(\mathrm{~B})$ has been selected as the parent structure for designing the new HEDCs.

It is also fascinating to state that the $N$-hydrogen atom in structure $\mathrm{B}$ can be substituted by additional functional groups. Among the functional groups, the $-\mathrm{NO}_{2},-\mathrm{N}-\mathrm{NO}_{2}$ and $-\mathrm{NF}_{2}$ groups are important groups in the synthesis of energetic materials because of their potential high density, energy and properties as solid propellant oxidizers 9 . However, when attempting to synthetize the HEDCs with multiple $-\mathrm{NO}_{2},-\mathrm{N}-\mathrm{NO}_{2}$, and $-\mathrm{NF}_{2}$ groups, it may be of great danger to humans and the environment both in synthesis and performance tests. Fortunately, computer simulation, as an effective way in screening promising explosives without these shortcomings, provides us an efficient way to predict the detonation properties of the above-mentioned groups.<smiles>O=C1N([N+](=O)[O-])CN([N+](=O)[O-])CN1[N+](=O)[O-]</smiles>

A<smiles>N=C1C([N+](=O)[O-])CN([N+](=O)[O-])CN1[N+](=O)[O-]</smiles>

B

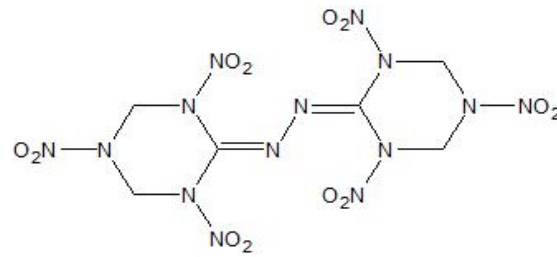

$\mathbf{E}$<smiles>O=[N+]([O-])N1CN([N+](=O)[O-])C(=[N+]([O-])[O-])N([N+](=O)[O-])C1</smiles>

C

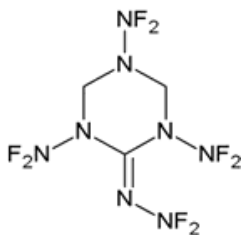

D

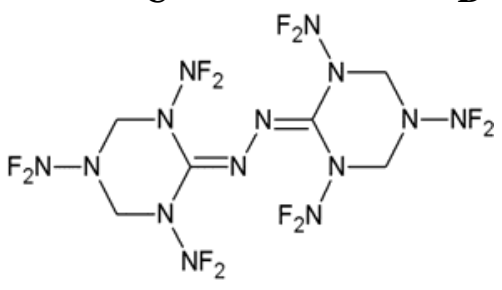

$\mathbf{F}$

Figure 1. Molecular frameworks $(\mathrm{A}=1,3,5$-trinitro-1,3,5-triazinan-2-one, $\mathrm{B}=1,3,5$-trinitro-1,3,5triazinan-2-imine, $\mathrm{C}=N, 1,3,5$-tetranitro-1,3,5-triazinan-2-imine, $\mathrm{D}=2$-(difluorohydrazinylidene)$N, N, N^{\prime}, N^{\prime}, N^{\prime \prime}, N^{\prime \prime}$-hexafluoro-1,3,5-triazinane-1,3,5-triamine, $\mathrm{E}=2,2^{\prime}$-hydrazine-1,2-diylidenebis(1,3,5-trinitro-1,3,5-triazinane), $\mathrm{F}=2,2^{\prime}$-hydrazine-1,2-diylidenebis( $N, N, N^{\prime}, N^{\prime}, N^{\prime \prime}, N^{\prime \prime}$-hexafluoro1,3,5-triazinane-1,3,5-triamine))

In the present study, four novel theoretical HEDCs (Figure 1, compounds C,D,E and F) have been designed based on the structure of Keto RDX. The molecular geometry, heat of formation, thermodynamic properties, thermal stability and detonation properties were investigated by using density functional theory (DFT) method ${ }^{10,11}$. The feasible synthetic route for the Keto RDX derivatives is also proposed via retrosynthetic analysis. All these results provide useful information for a better understanding of the compounds.

\section{Computational Method}

Computations were performed with the Gaussian $03^{12}$ package at $\mathrm{B} 3 \mathrm{LYP}^{13,14}$ method with $6-31 G(d, p)$ basic set ${ }^{15}$. The geometric parameters were optimizable and no constraints were imposed on molecular structure during the optimization process. Vibrational frequencies were calculated for the optimized structures to enable characterization of the nature of stationary points, zero-point energy (ZPE) and thermal correction $\left(H_{\mathrm{T}}\right)$. The optimized structure was characterized to be true local energy minima on potential energy surfaces without imaginary frequencies. On the basis of the principle of statistical thermodynamics ${ }^{16}$, the standard molar heat capacity $\left(C_{p . m}^{\theta}\right)$, standard molar entropy $\left(S_{m}^{\theta}\right)$ and standard molar enthalpy $\left(H_{m}^{\theta}\right)$ from 200 to $800 \mathrm{~K}$ were derived from the scaled frequencies using a self-compiled program. 
The B3LYP/6-31G (d,p) method ${ }^{17,18}$ was used to evaluate BDEs and HOFs of interested molecules. Calculation of the HOFs of the derivatives is necessary to determine their detonation properties. To obtain accurate HOF's values, isodesmic reactions, in which the equivalency of the bonds and electronic pairs in the reactant has been maintained not only in both products and reactants, but also can counterbalance the error in the electronic correlation energies, were designed. The feasibility of this approach for the estimation of accurate HOF of High Energy Density Materials has been previously demonstrated ${ }^{18,19}$.

The isodesmic reaction that was employed to calculate the HOF's of the Keto RDX derivatives at $298.15 \mathrm{~K}$ can be written as:

$$
\begin{aligned}
\mathrm{C}_{3} \mathrm{H}_{4} \mathrm{~N}_{4} \mathrm{R}_{4}+4 \mathrm{NH}_{3} \rightarrow \mathrm{C}_{3} \mathrm{~N}_{4} \mathrm{H}_{8}+4 \mathrm{NH}_{2} \mathrm{R} \\
\mathrm{C}_{6} \mathrm{H}_{8} \mathrm{~N}_{8} \mathrm{R}_{6}+6 \mathrm{NH}_{3} \rightarrow \mathrm{C}_{6} \mathrm{~N}_{8} \mathrm{H}_{14}+6 \mathrm{NH}_{2} \mathrm{R}
\end{aligned}
$$

Where $\mathrm{R}=-\mathrm{NO}_{2}$ or $-\mathrm{NF}_{2}$. Given the isodesmic reactions (1-2), the HOF's can be calculated from the following equation:

$$
\Delta H_{298.15 \mathrm{~K}}=\Sigma \Delta H_{\mathrm{f}, \mathrm{P}}-\Sigma \Delta H_{\mathrm{f}, \mathrm{R}}
$$

$\Delta H_{\mathrm{f}, \mathrm{P}}$ and $\Delta H_{\mathrm{f}, \mathrm{R}}$ in the above given equation represent the HOFs of the products and reactants at $298.15 \mathrm{~K}$, respectively. Thus, the HOFs of the Keto RDX derivatives can be determined when the heat of reaction $\Delta H_{298.15 \mathrm{~K}}$ is known. On the other hand, the HOFs at $298.15 \mathrm{~K}$ can be defined by the following equation:

$$
\Delta H_{298.15 \mathrm{~K}}=\Delta E_{298.15 \mathrm{~K}}+\Delta(P V)=\Delta E_{0}+\Delta \mathrm{ZPE}+\Delta H_{\mathrm{T}}+\Delta n R T
$$

Here, $\Delta E_{298.15 \mathrm{~K}}$ and $\Delta E_{0}$ are the change in total energy between the products and reactants at $298.15 \mathrm{~K}$ and $0 \mathrm{~K}$, respectively; $\triangle \mathrm{ZPE}$ is the difference between the zero-point energy (ZPE) of the products and reactants, and $\Delta H_{\mathrm{T}}$ is the thermal correction from $0 \mathrm{~K}$ to $298.15 \mathrm{~K}$. For reactions in the gas phase, $\Delta(P V)$ equals $\Delta n R T$, and for isodesmic reactions, $\Delta n=0$.

The experimental HOFs of the reference compounds $\mathrm{NH}_{3}$ and $\mathrm{NH}_{2} \mathrm{NO}_{2}$ are available ${ }^{20,21}$. As the experimental $\mathrm{HOF}$ of $\mathrm{C}_{3} \mathrm{~N}_{4} \mathrm{H}_{8}, \mathrm{C}_{6} \mathrm{~N}_{8} \mathrm{H}_{14}$ and $\mathrm{NH}_{2} \mathrm{NF}_{2}$ are unavailable, additional calculation were carried out at the $\mathrm{G} 2$ level $^{22}$ from the atomization reaction: $\mathrm{C}_{\mathrm{a}} \mathrm{H}_{\mathrm{b}} \mathrm{N}_{\mathrm{c}} \mathrm{O}_{\mathrm{d}} \rightarrow \mathrm{aC}(\mathrm{g})+\mathrm{bH}(\mathrm{g})+$ $\mathrm{cN}(\mathrm{g})+\mathrm{dO}(\mathrm{g})$ to predict its HOF accurately. Thus, the HOFs of the target molecules can be calculated out via Eqs. 1-4 in combination with the atomization reaction described.

However, the condensed phase of most energetic compounds are solid, and thus, the calculation of the detonation properties for such compounds requires solid-phase HOFs $\left(\Delta H_{\mathrm{f}, \text { solid }}\right)$ rather than gas-phase HOFs $\left(\Delta H_{\mathrm{f}, \mathrm{gas}}\right)$. Therefore, $\Delta H_{\mathrm{f}, \mathrm{gas}}$ was converted to $\Delta H_{\mathrm{f}, \text { solid }}$ according to Hess's law using the following formula ${ }^{23}$ :

$$
\Delta H_{\mathrm{f}, \text { solid }}=\Delta H_{\mathrm{f}, \mathrm{gas}}-\Delta H_{\mathrm{f}, \mathrm{sub}}
$$

where $\Delta H_{\text {sub }}$ denotes, the heat of sublimation.

In addition, Politzer et $a l .^{24,25}$ found that the heat of sublimation of energetic compounds correlates well with the molecular surface area and electrostatic interaction index $V O_{t o t}^{2}$ using the following expression:

$$
\Delta H_{\text {sub }}=a(S A)^{2}+b\left(v \sigma_{\text {tot }}^{2}\right)^{0.5}+c
$$

In this equation, $S A$ stands for the surface area of the $0.001 \mathrm{e} \mathrm{bohr}^{-3}$ isosurface for the electronic density of the molecule; $v$ is the degree of balance between the positive and negative potentials on the isosurface and $O_{t o t}^{2}$ is a measure of the variability of the electrostatic potential on the molecular surface. Byrd and Rice et al. calculated the values for $\Delta H_{\text {sub }}$ of CHNO 
CHNO systems using Eq. 6, and the coefficients a, b, and c were determined to be $\mathrm{a}=2.670 \times$ $10^{-4} \mathrm{kcal} \mathrm{mol}^{-1} \mathrm{~A}^{-4}, \mathrm{~b}=1.650 \mathrm{kcal} \mathrm{mol}^{-1}$, and $\mathrm{c}=2.966 \mathrm{kcal} / \mathrm{mol}^{26}$. The descriptors $S A, v$, and $\mathrm{O}_{t o t}^{2}$ were calculated using the computational procedures as described by Bulat $e t a l^{27}$. This approach has been demonstrated to be a reliable method for the prediction of the heats of sublimation of many energetic compounds ${ }^{28,29}$.

The detonation velocity and detonation pressure were estimated by the empirical KamletJacobs equations ${ }^{30}$ :

and

$$
D=(1.011+1.312 \rho)\left(N M^{0.5} Q^{0.5}\right)^{0.5}
$$

$$
P=1.558 \rho^{2} N M^{0.5} Q^{0.5}
$$

Where $\rho$ is the loaded density of the explosive $\left(\mathrm{g} \mathrm{cm}^{-3}\right) ; D$ is the detonation velocity $\left(\mathrm{km} \mathrm{s}^{-1}\right)$; $P$ is the detonation pressure (GPa); $N$ is the number of moles of detonation gases per-gram explosive $\left(\mathrm{mol} \mathrm{g}^{-1}\right) ; M$ is the average molecular weight of these gases $\left(\mathrm{g} \mathrm{mol}^{-1}\right)$; and $Q$ is the heat of detonation ( $\mathrm{cal} \mathrm{g}^{-1}$ ). The variables $N, M$, and $Q$ were calculated according to Table $1^{26-31}$. The value of $\rho$ can be calculated as $\mathrm{M} / \mathrm{V}$, where $\mathrm{M}$ is the molecular mass $\left(\mathrm{g} \mathrm{mol}^{-1}\right)$, and $\mathrm{V}$ is the volume defined as the space inside a cloud of electron density of $0.001 \mathrm{e} \mathrm{Bohr}^{-3}$.

Table 1. Formulas for calculating the values of $N, M$, and $Q$ for an explosive $\mathrm{C}_{a} \mathrm{H}_{b} \mathrm{O}_{c} \mathrm{~N}_{d}$

\begin{tabular}{cccc}
\hline \multirow{2}{*}{ Parameters } & \multicolumn{3}{c}{ Stoichiometric ratio } \\
\cline { 2 - 4 } & $\mathrm{C} \geq 2 \mathrm{a}+0.5 \mathrm{~b}$ & $2 \mathrm{a}+0.5 \mathrm{~b}>\mathrm{c} \geq 0.5 \mathrm{~b}$ & $0.5 \mathrm{~b}>\mathrm{c}$ \\
\hline$N$ & $(\mathrm{~b}+2 \mathrm{c}+2 \mathrm{~d}) / 4 M$ & $(\mathrm{~b}+2 \mathrm{c}+2 \mathrm{~d}) / 4 M$ & $(\mathrm{~b}+\mathrm{d}) / 2 M$ \\
$M$ & $4 M /(\mathrm{b}+2 \mathrm{c}+2 \mathrm{~d})$ & $(56 \mathrm{~d}+88 \mathrm{c}-8 \mathrm{~b}) /(\mathrm{b}+2 \mathrm{c}+2 \mathrm{~d})$ & $(2 \mathrm{~b}+28 \mathrm{~d}+32 \mathrm{c})$ \\
\multirow{2}{*}{$Q^{*} 10^{-3}$} & $(28.9 \mathrm{~b}+94.05 \mathrm{a}+0.239 \Delta$ & {$[(\mathrm{b}+\mathrm{d})$} \\
& $\left.H_{\mathrm{f}}\right) / M$ & $\left.(\mathrm{c} / 2-\mathrm{b} / 4)+0.239 \Delta H_{\mathrm{f}}\right] / M$ & $(57.8 \mathrm{c}+0.239 \Delta$ \\
\end{tabular}

$a, b, c$, and $d$ stand for the number of $C, H, O$, and $N$ atoms in the explosive molecule, respectively

$M$ in the formula is the molecular weight of the explosive $\left(\mathrm{g} \mathrm{mol}^{-1}\right) ; \Delta H_{\mathrm{f}}$ is the heat of formation of the explosive $\left(\mathrm{kJ} \mathrm{mol}^{-1}\right)$.

However, the results for $\rho$ obtained using this equation might have significant errors for some systems, such as molecules that can form strong hydrogen bonds. Therefore, Politzer et al. ${ }^{32}$ suggested that $\rho$ should be corrected for the better reflect of the effects of intermolecular interactions in crystals, and the modified equation to calculate the $\rho$ of CHNO energetic materials is written as follows:

$$
\rho=\alpha_{1}(M / V)+\beta_{1}\left(V O_{t o t}^{2}\right)+\gamma_{1}
$$

where $v$ is the degree of balance between the positive and negative potentials on the isosurface; $O_{t o t}^{2}$ is a measure of the variability of the electrostatic potential on the molecular surface; and the coefficients $\alpha_{1}, \beta_{1}$, and $\gamma_{1}$ with values of $0.9183,0.0028$, and 0.0443 , respectively, was adopted from Politzer's study.

The strength of bonding within a molecule, which can be evaluated using BDEs, plays an important role in understanding its thermal stability ${ }^{33}$. Basically, it is defined as the enthalpy change at $298 \mathrm{~K}$, and a value of $1.01 \times 10^{5} \mathrm{~Pa}$ is assigned for the chemical bond dissociation in a molecule $\mathrm{A}-\mathrm{B}$ as follows ${ }^{34}$ :

$$
\begin{gathered}
\mathrm{A}-\mathrm{B}_{(\mathrm{g})} \rightarrow \mathrm{A}_{(\mathrm{g})}+\mathrm{B}_{(\mathrm{g})} \quad \text { and } \\
\Delta H_{298}(\mathrm{~A}-\mathrm{B})=\left[\Delta_{\mathrm{f}} H_{298}\left(\mathrm{~A}^{\circ}\right)+\Delta_{\mathrm{f}} H_{298}\left(\mathrm{~B}^{\circ}\right)\right]-\Delta_{\mathrm{f}} H_{298}(\mathrm{~A}-\mathrm{B})
\end{gathered}
$$


In the above stated equations, $\mathrm{A}-\mathrm{B}$ denotes the neutral molecule, $\mathrm{A}^{\circ}$ and $\mathrm{B}^{\circ}$ represent the corresponding product radicals after bond dissociation; $\Delta H_{298}(\mathrm{~A}-\mathrm{B})$ is the bond dissociation enthalpy of A-B; and $\Delta_{\mathrm{f}} H_{298}\left(\mathrm{~A}^{\circ}\right), \Delta_{\mathrm{f}} H_{298}\left(\mathrm{~B}^{\circ}\right)$, and $\Delta_{\mathrm{f}} H_{298}(\mathrm{~A}-\mathrm{B})$ are the enthalpies of formation for the free radicals and the parent molecule at $298 \mathrm{~K}$, respectively. It is evident that the reaction enthalpy of the homolysis bond reaction exclusively depends on the relative enthalpies of formation of the reactant and product.

For many organic compounds, $\mathrm{BDE}_{(\mathrm{A}-\mathrm{B})}$ and $\Delta \mathrm{H}_{298}(\mathrm{~A}-\mathrm{B})$ are nearly equivalent numerically; thus, the terms "bond dissociation energy" and "bond dissociation enthalpy" often appear interchangeably in the literature ${ }^{35}$. Therefore, the BDEs of the homolytic bond can be calculated by the following equation:

$$
\mathrm{BDE}_{0}(\mathrm{~A}-\mathrm{B}) \rightarrow E_{0}\left(\mathrm{~A}^{*}\right)+E_{0}\left(\mathrm{~B}^{\circ}\right)-E_{0}(\mathrm{~A}-\mathrm{B})
$$

The $\mathrm{BDE}$ corrected for the ZPE can be calculated using Eq. (12):

$$
\mathrm{BDE}(\mathrm{A}-\mathrm{B})_{\mathrm{ZPE}}=\mathrm{BDE}_{0}(\mathrm{~A}-\mathrm{B})+\Delta E_{\mathrm{ZPE}}
$$

Here $\Delta \mathrm{E}_{\mathrm{ZPE}}$ is the difference between the $\mathrm{ZPEs}$ of the products and reactants.

\section{Results and Discussion}

\section{Molecular Geometry and Electronic Structure}

Since all the calculations are based on the optimized structure, it is necessary to examine the geometric structure of the Keto RDX derivatives before discussing the various properties. The results show that all the optimized structures are characterized to be true local energy minima on the potential energy surfaces without imaginary frequencies. Besides, all the calculated bond lengths are between the normal $\mathrm{C}-\mathrm{N}, \mathrm{N}-\mathrm{N}$ bond lengths $(1.47 \AA$ and $1.45 \AA$, respectively) and normal $\mathrm{C}=\mathrm{N}$ bond lengths $(1.28 \AA)$. So, all the bonds tend to be average and form a big conjugative system, which may_facilitate the stability of the compounds.

The energy gap $(\Delta \mathrm{E})$ is one of the most important parameters for predicting the relative stability of compounds. Thus, the highest occupied molecular orbital (HOMO) energies, the lowest unoccupied molecular orbital (LUMO) energies, and the energy gaps $\left(\Delta \mathrm{E}_{\mathrm{LUMO}-\mathrm{HOMO}}\right)$ were calculated at the B3LYP/6-31G $(\mathrm{d}, \mathrm{p})$ level. Analysis of the molecular orbital can provide useful information on electronic structures ${ }^{36}$. It is proposed that the larger the energy gap of a compound, the lower is the reactivity in the chemical or photochemical processes with electron transfer ${ }^{37,38}$. The values are summarized in Table 2. It is evident that the energy gap $\Delta \mathrm{E}$ of compounds $\mathrm{D}$ and $\mathrm{F}$ are slightly higher than that of compounds $\mathrm{C}$ and $\mathrm{E}$, indicating that compound $\mathrm{D}$ and $\mathrm{F}$ may have a comparable chemical reactivity with compounds $\mathrm{C}$ and $\mathrm{E}$. Inspection of the MEPs for the compounds show that the positive potentials which slightly increases the stabilization to a compound, ranges at the center of the skeleton while the negative potentials appear to be distributed mostly on the oxygen or fluorine atom.

Table 2. Calculated HOMO and LUMO energies (a.u) and their energy gaps ( $\left.\triangle \mathrm{E}_{\mathrm{LUMO}-\mathrm{HOMO}}\right)$

\begin{tabular}{cccc}
\hline Compound & $\mathrm{E}_{\text {HOMO }}$ & $\mathrm{E}_{\text {LUMO }}$ & $\Delta \mathrm{E}$ \\
\hline $\mathrm{A}$ & -0.3098 & -0.0952 & 0.2146 \\
$\mathrm{~B}$ & -0.3010 & -0.1036 & 0.1974 \\
$\mathrm{C}$ & -0.3146 & -0.1165 & 0.1981 \\
$\mathrm{D}$ & -0.2775 & -0.0639 & 0.2135 \\
$\mathrm{E}$ & -0.2922 & -0.1180 & 0.1742 \\
$\mathrm{~F}$ & -0.2514 & -0.0680 & 0.1834 \\
\hline
\end{tabular}




\section{Infrared spectra and Thermodynamic properties}

Figure 2 presents the simulated IR spectrum of compounds C, D and E, F. There are several similar IR absorption bands between compounds C, D and E, F. The modes in $3000-3300 \mathrm{~cm}^{-1}$ are associated with the $\mathrm{C}-\mathrm{H}$ stretching vibration of compounds. The remarkable peak in 1600$1800 \mathrm{~cm}^{-1}$ is associated with the $\mathrm{N}=\mathrm{O}$ or $\mathrm{N}-\mathrm{F}$ asymmetric stretching of $-\mathrm{NO}_{2}$ and $-\mathrm{NF}_{2}$ groups. The band at around $1000 \mathrm{~cm}^{-1}$ is composed of the $\mathrm{N}-\mathrm{N}$ asymmetric stretching of compound with $\mathrm{C}-\mathrm{H}$ twisting out of plane. The bands less than $900 \mathrm{~cm}^{-1}$ that belong to the fingerprint spectrum, are mainly caused by the deformation of the skeleton structure and the bending vibration of $\mathrm{C}-\mathrm{H}$ and $\mathrm{C}-\mathrm{C}$ bonds.
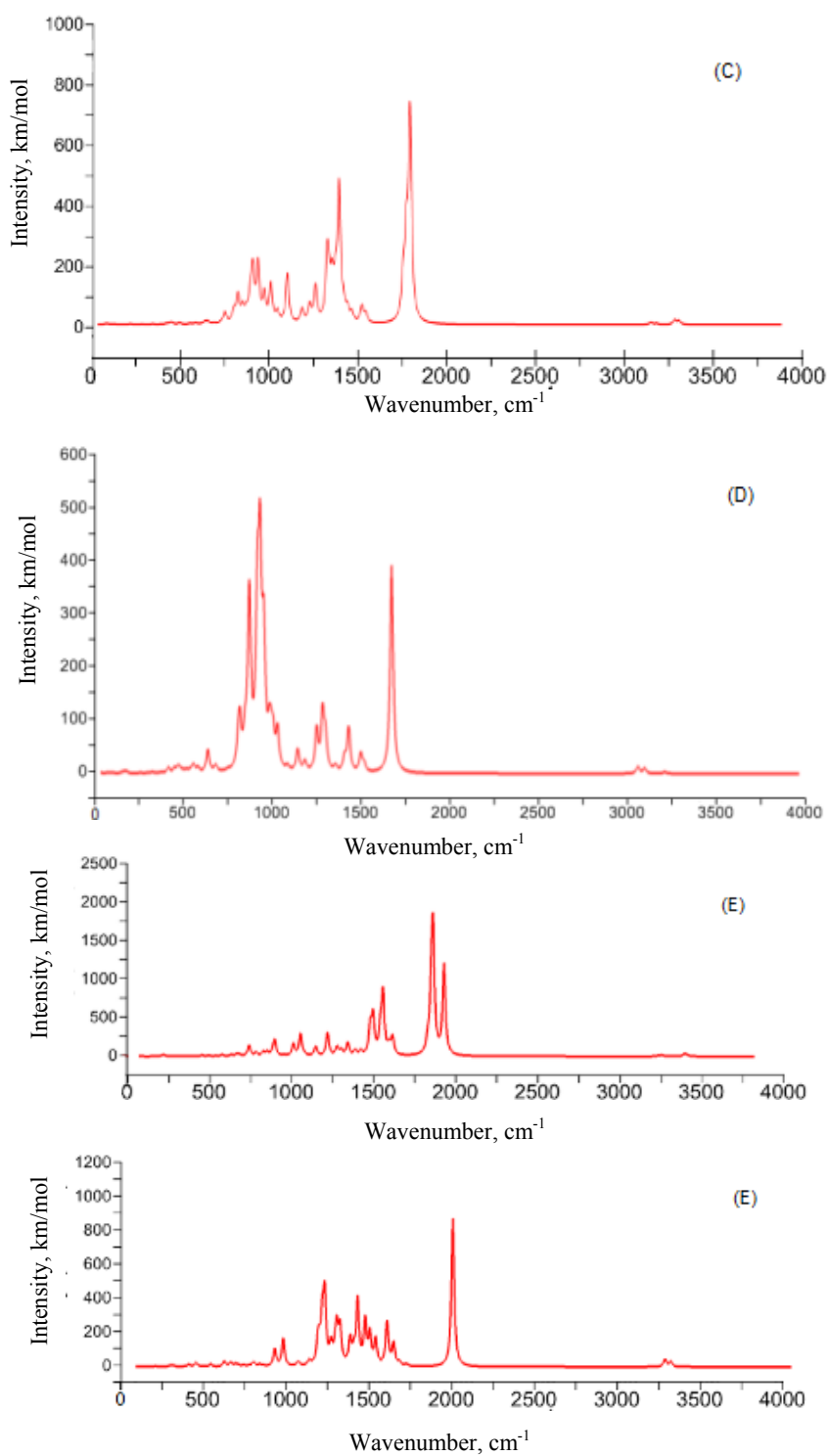

Figure 2. Simulated IR spectra for the Keto RDX derivatives at the B3LYP/6-31G(d,p) level. 
Based on scaled frequencies and the principle of statistic thermodynamics, thermodynamic properties such as standard molar heat capacity $\left(C_{p, m}^{\theta}\right)$, standard molar entropy $\left(S_{m}^{\theta}\right)$ and standard molar enthalpy $\left(H_{m}^{\theta}\right)$ ranging from 200 to $800 \mathrm{~K}$ are calculated using a self-compiled program to predic their thermodynamic properties. The values are summerized in Table 3. It is found that all thermodynamic functions increase with temperature evidently. Taking compound $\mathrm{E}$ as an examples, the Temperature-dependent relations for $C_{p, m}^{\theta}$ $S_{m}^{\theta}$ and $H_{m}^{\theta}$ in the range of 200-800 K are shown in Figure 3.

It can be seen that $C_{p, m}^{\theta}, S_{m}^{\theta}$ and $H_{m}^{\theta}$ increase evidently with the increasing temperature. This is because the main contributions to the thermodynamic functions are from the translation and rotation of molecules when the temperature is low; however, at higher temperature, the vibrations are intensified and therefore make more contributions to the thermodynamic properties which lead to the increase in the thermodynamic functions. The data provide useful information on the thermodynamic properties of the compound under discussion
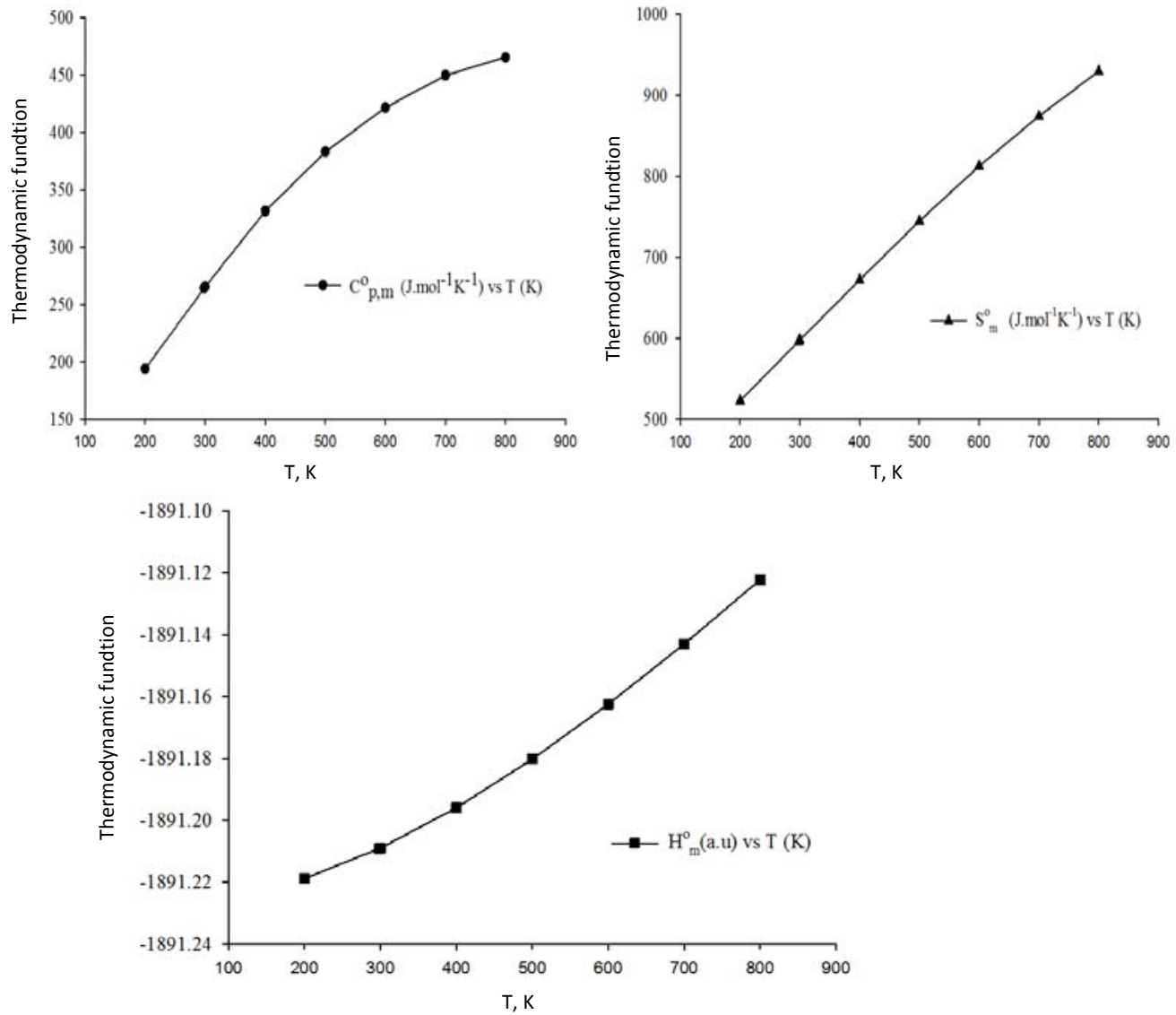

Figure 3. Relationships between the thermodynamic functions $\left(C_{p, m}^{\theta}, S_{m}^{\theta}\right.$ and $\left.H_{m}^{\theta}\right)$ and temperature $(\mathrm{T} / \mathrm{K})$ for Compound $\mathrm{E}$ 
Table 3. Thermodynamic properties of the Keto RDX derivatives at different temperatures ${ }^{\mathrm{a}}$

\begin{tabular}{|c|c|c|c|c|c|c|c|c|c|}
\hline Compounds & $\mathrm{T}$ & $200 \mathrm{~K}$ & $298.15 \mathrm{~K}$ & $300 \mathrm{~K}$ & $400 \mathrm{~K}$ & $500 \mathrm{~K}$ & $600 \mathrm{~K}$ & $700 \mathrm{~K}$ & $800 \mathrm{~K}$ \\
\hline \multirow{3}{*}{ A } & $e_{\mathrm{Bm}}^{\tilde{f}}$ & 110.15 & 147.97 & 148.65 & 180.72 & 203.98 & 220.85 & 230.42 & 235.32 \\
\hline & $5_{\mathrm{m}}^{\mathrm{i}}$ & 389.71 & 437.82 & 438.66 & 483.96 & 525.41 & 563.25 & 596.22 & 626.17 \\
\hline & $K_{\mathrm{u}}^{\sigma}$ & -971.293936 & -971.288380 & -971.288258 & -971.280929 & -971.272273 & -971.262701 & -971.252304 & -971.241463 \\
\hline \multirow{3}{*}{ B } & $\mathrm{e}_{\mathrm{p}}^{\mathrm{f}}$ & 111.01 & 151.72 & 152.45 & 187.22 & 212.00 & 229.65 & 239.53 & 244.7 \\
\hline & $S_{\mathrm{m}}^{\bar{m}}$ & 388.10 & 437.41 & 438.32 & 485.42 & 529.35 & 569.09 & 604.01 & 635.90 \\
\hline & $R_{\mathrm{m}}^{2}$ & -951.397632 & -951.391964 & -951.391840 & -951.384261 & -951.375301 & -951.365325 & -951.354468 & -951.343157 \\
\hline \multirow{3}{*}{ C } & $\mathrm{E}_{\mathrm{p}}^{\mathrm{n}}$ & 129.17 & 174.6 & 175.39 & 212.74 & 237.77 & 256.39 & 267.37 & 272.91 \\
\hline & $S_{\mathrm{D}}^{\mathrm{E}}$ & 421.16 & 474.32 & 475.3 & 525.83 & 573.61 & 616.74 & 654.9 & 689.53 \\
\hline & $H_{\mathrm{m}}^{\mathrm{w}}$ & -1155.853240 & -1155.846760 & -1155.846620 & -1155.838070 & -1155.827970 & -1155.816760 & -1155.804680 & -1155.792130 \\
\hline \multirow{3}{*}{ D } & $e_{\mathrm{p}}^{\tilde{n}}$ & 142.22 & 190.62 & 191.39 & 228.85 & 252.59 & 264.78 & 271.1 & 273.84 \\
\hline & 5 흐 & 433.48 & 493.10 & 494.17 & 550.86 & 601.88 & 648.08 & 688.35 & 720.84 \\
\hline & $K_{\mathrm{m}}^{\boldsymbol{E}}$ & -1352.646580 & -1352.639430 & -1352.639270 & -1352.629940 & -1352.619000 & -1352.607071 & -1352.594820 & -1352.582180 \\
\hline \multirow{3}{*}{$\mathbf{E}^{\mathrm{b}}$} & $\mathrm{C}_{\mathrm{p}}^{\tilde{f} \mathrm{~m}}$ & 193.76 & 264.05 & 265.36 & 331.39 & 383.09 & 421.62 & 449.79 & 465.42 \\
\hline & $S_{\mathrm{m}}^{\tilde{n}}$ & 522.64 & 596.26 & 597.66 & 671.88 & 744.73 & 812.6 & 874.35 & 929.71 \\
\hline & $K_{\mathrm{m}}^{ \pm}$ & -1891.21886 & -1891.20922 & -1891.20901 & -1891.19603 & -1891.18028 & -1891.16242 & -1891.14298 & -1891.12216 \\
\hline \multirow{3}{*}{$\mathbf{F}^{\mathrm{b}}$} & $e_{\mathrm{p}}^{\tilde{u}}$ & 210.83 & 285.35 & 286.66 & 350.78 & 404.34 & 441.78 & 461.11 & 470.11 \\
\hline & $S_{\mathrm{m}}^{\dot{d}}$ & 539.74 & 622.72 & 624.22 & 704.05 & 781.05 & 850.73 & 913.23 & 970.44 \\
\hline & ${ }_{\mathrm{m}}^{\boldsymbol{F}}$ & -2185.96808 & -2185.95759 & -2185.95736 & -2185.94335 & -2185.92668 & -2185.90795 & -2185.88765 & -2185.86658 \\
\hline
\end{tabular}

${ }^{a}$ Units: $T: K ; \mathcal{E}_{\mathrm{m}}^{\tilde{m}}: \mathrm{m}_{\mathrm{m}}{ }^{-1} ; S_{\mathrm{m}}^{\mathrm{m}}: J . \mathrm{mol}^{-1} ; \boldsymbol{H}_{\mathrm{m}}^{\mathrm{o}}:$ a.u ${ }^{b}$ For compounds $E$ and $F$ thermodynamic properties were at RHF/6-31G(d,p) level 


\section{HoF Properties}

The heat of formation, which is a basic property of HEDCs, is usually taken as the indicator of the "energy content" and is one of the most important thermo chemical properties of energetic materials. The DFT method has proved reliable for estimating HOF through appropriate reactions $\mathrm{s}^{39,40}$. Thereby, heat of formation is frequently considered when the HEDCs are designed. Table 4 shows the total energies $\left(E_{0}\right)$, thermal corrections $\left(H_{\mathrm{T}}\right)$, zero-point energies $(\mathrm{ZPE})$, and HOFs for the reference compounds being enlisted in the isodesmic reaction. Table 5 summarizes the total energies $\left(E_{0}\right)$, thermal corrections $\left(H_{\mathrm{T}}\right)$, zero-point energies(ZPE) and solid-phase HOF $\left(\Delta H_{\mathrm{f}, \text { solid }}\right)$ of the compounds at the B3LYP/6-31G(d,p) level. From Table 5, it is obvious that when the $\mathrm{H}$ atom of the $\mathrm{N}-\mathrm{H}$ in $\mathrm{C}_{3} \mathrm{H}_{5} \mathrm{~N}_{7} \mathrm{O}_{6}$ (B) is replaced by $-\mathrm{NO}_{2}$ and $-\mathrm{NF}_{2}$ groups, the HOFs of the compounds $\mathrm{C}$ and $\mathrm{D}$ are up to $279.78 \mathrm{~kJ} \cdot \mathrm{mol}^{-1}$ and $163.83 \mathrm{~kJ} \cdot \mathrm{mol}^{-1}$ respectively. On the other hand, the HOF reduced sharply from $279.78 \mathrm{~kJ} \cdot \mathrm{mol}^{-1}$ and $163.83 \mathrm{~kJ} \cdot \mathrm{mol}^{-1}$ when the $-\mathrm{NO}_{2}$ groups in compound $\mathrm{C}$ are replaced by the $-\mathrm{NF}_{2}$ groups in compound $\mathrm{D}$. This indicates that $\mathrm{NO}_{2}$ and $-\mathrm{NF}_{2}$ group have a superiority in increasing the HOF.

Table 4. Calculated total energies $\left(E_{0}, \mathrm{au}\right)$, thermal corrections $\left(H_{\mathrm{T}}, \mathrm{kJ} \cdot \mathrm{mol}^{-1}\right)$, zero-point energies (ZPE, kJ.mol ${ }^{-1}$ ) and heats of formation (HOFs, $\mathrm{kJ} . \mathrm{mol}^{-1}$ ) for the reference compounds

\begin{tabular}{ccccc}
\hline Compound & $E_{0}$ & $H_{\mathrm{T}}$ & $\mathrm{ZPE}$ & $\mathrm{HOF}$ \\
\hline $\mathrm{NH}_{3}$ & -56.557769 & 9.60 & 88.62 & -45.94 \\
$\mathrm{NH}_{2} \mathrm{NO}_{2}$ & -261.037824 & 11.67 & 101.61 & 6.69 \\
$\mathrm{NH}_{2} \mathrm{NF}_{2}$ & -310.230386 & 12.69 & 91.81 & -25.0 \\
$\mathrm{C}_{3} \mathrm{~N}_{4} \mathrm{H}_{8}$ & -338.137956 & -8.34 & 354.22 & 51.04 \\
$\mathrm{C}_{6} \mathrm{~N}_{8} \mathrm{H}_{14}$ & -674.8242269 & 29.25 & 620.67 & 166.78 \\
\hline
\end{tabular}

However, the HOFs of compounds C,D,E and F are higher than that of un-substituted compound $\mathrm{A}$. This property has kindled the interest of scientists to devote their efforts to synthetize $\mathrm{HEDCs}$ with multi $-\mathrm{NF}_{2}$ and $-\mathrm{NO}_{2}$ groups.

Table 5. Calculated total energies $\left(E_{0}, \mathrm{au}\right)$, thermal corrections $\left(H_{\mathrm{T}}, \mathrm{kJ} \cdot \mathrm{mol}^{-1}\right)$, zero-point energies (ZPE, kJ.mol ${ }^{-1}$ ), and heats of formation $\left(\mathrm{HOFs}, \mathrm{kJ} \cdot \mathrm{mol}^{-1}\right.$ ) for the Keto RDX derivatives

\begin{tabular}{ccccr}
\hline Compound & $E_{0}$ & $H_{\mathrm{T}}$ & ZPE & $\Delta H_{\mathrm{f}}$, solid \\
\hline A & -971.429269 & 24.04 & 316.60 & -45.46 \\
B & -951.539637 & 23.46 & 348.75 & 206.23 \\
C & -1155.997385 & 28.22 & 351.44 & 277.73 \\
D & -1352.778236 & 31.84 & 318.03 & 181.75 \\
E & -1901.845745 & 37.23 & 716.58 & 527.18 \\
F & -2196.972423 & 42.37 & 662.33 & 439.28 \\
\hline
\end{tabular}

\section{Detonation properties}

The detonation velocity and detonation pressure are two important parameters for HEDCs. The Kamlet-Jacobs equations show that $\rho$ is a key factor to influence Detonation velocity $(D)$ and Detonation pressure $(P)$. Thus, density is one of the most important physical properties for all energetic materials. For the derivatives evaluated in this study, the theoretical density was replaced with the loading density, and the detonation properties were calculated. The values of $\rho, D$ and $P$ of compounds are listed in Table 6 . 
Table 6. Detonation properties of the Keto RDX derivatives and other relative HEDCs

\begin{tabular}{cccc}
\hline Compound & $\rho\left(\mathrm{g} \mathrm{cm}^{-1}\right)$ & $D\left(\mathrm{~km} \mathrm{~s}^{-1}\right)$ & $P(\mathrm{GPa})$ \\
\hline A & $1.86(1.93)^{\mathrm{a}}$ & $8.97(8.814)^{\mathrm{a}}$ & $36.45(37.98)^{\mathrm{a}}$ \\
$\mathrm{B}$ & 1.84 & 8.97 & 36.17 \\
C & 1.88 & 9.41 & 40.29 \\
$\mathrm{D}$ & 2.09 & 10.71 & 55.37 \\
$\mathrm{E}$ & 1.93 & 9.42 & 40.99 \\
F & 2.02 & 10.85 & 55.79 \\
RDX $^{\mathrm{a}}$ & 1.82 & 8.75 & 34.00 \\
HMX $^{\mathrm{a}}$ & 1.91 & 9.0 & 30.00 \\
CL-20 & $2.04^{\mathrm{b}}$ & $9.38^{\mathrm{b}}$ & $44.64^{\mathrm{c}}$ \\
\hline
\end{tabular}

${ }^{a}$ Experimental value from Ref..41, ${ }^{b}$ Experimental value from Ref.. $43^{c}$ Calculated value from Ref. 19

It apparent from the substantiated Table 6, that all the compounds have excellent detonation properties. Compounds $\mathrm{D}$ and $\mathrm{F}$ have proved to have higher $\rho, D$ and $P$ values than that of compounds $\mathrm{C}$ and $\mathrm{E}$. This indicates that $-\mathrm{NO}_{2}$, and $-\mathrm{NF}_{2}$ groups are effective units for improving the detonation properties of a compound, especially the $\mathrm{NF}_{2}$ group. This supports the conclusion that although $-\mathrm{NF}_{2}$ decreases the $\mathrm{HOF}$ a little, it increases $\rho$ to a greater extent and thus makes compounds $\mathrm{D}$ and $\mathrm{F}$ possess the highest Detonation velocity $(D)$ and Detonation pressure $(P)$. Whereas, $-\mathrm{NO}_{2}$ increases HOF and $\rho$ moderately and thus makes Detonation velocity $(D)$ and Detonation pressure $(P)$ of compounds $\mathrm{C}$ and $\mathrm{E}$ which stands next to compound $\mathrm{D}$ and $\mathrm{F}$. For a quick reference and comparison, the detonation properties of the well-known explosives RDX, HMX and CL-20 are also listed in Table 6. Clearly, the designed compounds possess higher $\rho$, Detonation velocity $(D)$ and Detonation pressure $(P)$ than that of RDX, HMX and CL20 and meet the quantitative criteria of a HEDC (that is, $\rho \approx 1.9 \mathrm{~g} \mathrm{~cm}^{-3}, \mathrm{D} \approx 9.0 \mathrm{~km} \mathrm{~s}^{-1}$, and $\mathrm{P} \approx 40.0 \mathrm{GPa}$ ). If these derivatives could be synthesized, they will have more exploitable values in the future.

\section{Bond dissociation energy $(B D E)$ and thermal stability}

Bond dissociation energy (BDE) of the trigger bond is another key parameter, which can provide useful information for understanding the stability and sensitivity of HEDCs. Generally, the smaller the energy is needed for breaking a bond, the weaker the bond is, and becomes a trigger bond when heated or assaulted: that is to say, the corresponding compound is more unstable, and has greater sensitivity. Thus, to elucidate the thermal stability of HEDCs, the BDE of the trigger bond must be studied. On the other hand, people now-a-days have reached a consensus that $-\mathrm{N}-\mathrm{NO}_{2}$ or $-\mathrm{N}-\mathrm{NF}_{2}$ bond often represents the primary cause of initiation reactivity of organic polynitro or difluoroamino compounds ${ }^{44,45}$. Therefore, the weakest $\mathrm{N}-\mathrm{N}$ bonds, which were screened according to the "principle of smallest bond order (PSBO)" (the smallest bond order is, the least stable is) ${ }^{46}$, were selected as the breaking bond to calculate bond dissociation energy (BDE) at B3LYP/6-31G(d,p) level.

The PBSO can be defined as follows: for a series of energetic materials with a similar molecular structure and pyrolysis mechanism, the smaller the overlap population of the trigger bond, the larger the impact sensitivity ${ }^{47}$. It is also should be pointed out that the weakest bond was selected as the breaking bond based on the Fuzzay bond order. Table 7 presents the BDEs of Keto RDX derivatives. 
Table 7. Calculated bond dissociation energies of trigger bond for the Keto RDX derivatives

\begin{tabular}{ccc}
\hline & \multicolumn{2}{c}{${\mathrm{N}-\mathrm{NO}_{2}}$} \\
\cline { 2 - 3 } Compound & $\mathrm{BDE}_{0}\left(\mathrm{~kJ} \mathrm{~mol}^{-1}\right)$ & $\mathrm{BDE}_{\mathrm{ZPE}}\left(\mathrm{kJ} \mathrm{mol}{ }^{-1}\right)$ \\
\hline $\mathrm{A}$ & 166.23 & 146.95 \\
$\mathrm{~B}$ & 160.82 & 140.53 \\
$\mathrm{C}$ & 141.29 & 130.57 \\
$\mathrm{D}$ & 136.19 & 116.10 \\
$\mathrm{E}$ & 79.90 & 57.22 \\
$\mathrm{~F}$ & 66.90 & 40.48 \\
\hline
\end{tabular}

From Table 7, it is clear that the values of BDEs of compounds $\mathrm{C}$ and $\mathrm{E}$ is higher than that of compounds $\mathrm{D}$ and $\mathrm{F}$. In other words, it is to say compounds $\mathrm{D}$ and $\mathrm{F}$ has a lower stability (higher sensitivity) than compounds $\mathrm{C}$ and $\mathrm{E}$ and may be exploded immediately when heated or assaulted. This is in harmonic agreement with the fact that $-\mathrm{NF}_{2}$ group is more sensitive than $-\mathrm{NO}_{2}$ group for an explosive because of the strong electron attracting. And thus the stability of the molecule lowers when $-\mathrm{NO}_{2}$ is substituted by $-\mathrm{NF}_{2}$. Furthermore, when taken the practical requirements into consideration, a quantitative criteria associated stability (BDE of the trigger bond) requirement, i.e., BDE $80 \sim 120 \mathrm{~kJ} \cdot \mathrm{mol}^{-1}$, is proposed and employed by Chung et al. to filtrate a potential $\mathrm{HEDC}^{48}$. Based on the law, it is found that the compounds satisfy the basic requirements and seem to be the potential HEDCs.

\section{Feasible synthetic routes}

Based on the above-calculated data, it is precise that the compounds are potential HEDCs with high detonation properties and exploitable values. Thus, the feasible synthetic routes for the two compounds are proposed in Figure 4. From the scheme, it is found that all of the crude materials are easily obtained with low price and provides a necessary condition for the mass industrial production. Besides, the synthetic routes are simple. The feasibility of the synthetic routes of the Keto RDX derivatives is designed as:

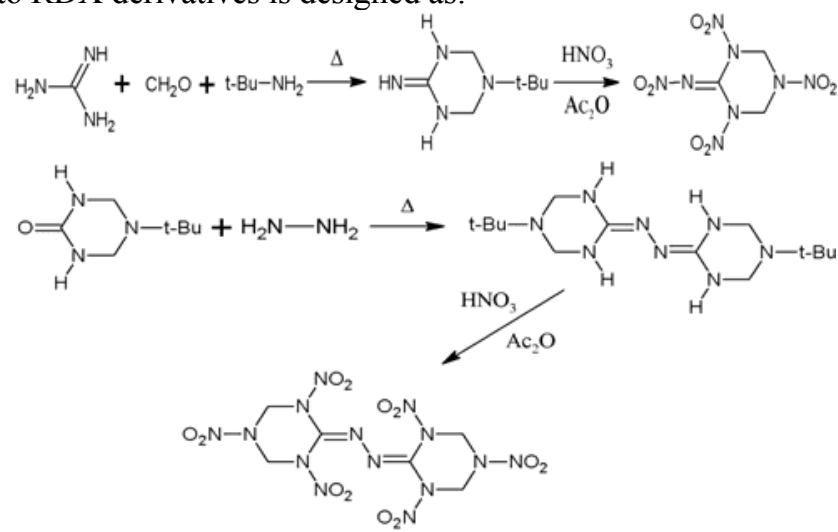

Figure 4. Synthetic routes of the Keto RDX derivatives

\section{Conclusion}

In the present work, the electronic structure, thermodynamic properties, heats of formation, detonation properties, and thermal stability were studied for novel explosives based on keto RDX skeleton $\mathrm{C}_{3} \mathrm{H}_{5} \mathrm{~N}_{7} \mathrm{O}_{6}$ by using the B3LYP/6-31G(d,p) method of DFT theory. Calculation results show that the compounds possess high positive heats of formation; 
the density and detonation properties of the Keto RDX derivatives are larger than that of RDX, HMX and CL-20. The bond dissociation energies of the pyrolysis initiation reaction was calculated at the B3LYP/6-31G(d,p) level indicated that the Keto RDX derivatives meet basic requirements and seem to be the potential HEDCs. Besides, the synthetic routes proposed are simple and feasible. All the data may provide useful information for a better understanding of physical and chemical properties of the compounds.

\section{References}

1. Hiyoshi R I, Kohno Y and Nakamura J, J Phys Chem A, 2004, 108(27), 5915-5920; DOI:10.1021/jp049118i

2. Jin X H, Hu B C, Jia H Q and Lv C X, Chem J Chin Univ., 2013, 34, 1685.

3. Turker L and Bayer C C, J Energy Mater., 2012, 30, 72.

4. Janning J D and Ball D W, J Mol Model, 2010, 16(5), 857-862; DOI:10.1007/s00894-009-0586-y

5. Willer R L, J Org Chem., 1984, 49(26), 5150-5154; DOI:10.1021/jo00200a027

6. Simpson R L, Urtiew P A, Ornellas D L, Moody G L, Scribner K J and Hoffman D M, Propellants Explos pyrotech., 1997, 22(5), 249-255; DOI:10.1002/prep.19970220502

7. Koppes W M, Chaykovsky M, Adolph G, Gilardi H G and George C, J Org Chem., 1987, 52(6), 1113-1119; DOI:10.1021/jo00382a025

8. Sikder A K, Sikder N, Bulakh N R and Sarwade D B, J Hazard Mater., 2003, 96(2-3), 109-119; DOI:10.1016/S0304-3894(02)00169-3

9. Wu Q, Pan Y, Zhu W and Xiao H, J Mol Model., 2013, 19(4), 1853-1864; DOI:10.1007/s00894-013-1756-5

10. Zhao G Z and Lu M, Bull Korean Chem Soc., 2012, 33(6), 1913; DOI:10.5012/bkcs.2012.33.6.1913

11. Cho H G, Bull Korean Chem Soc, 2013, 34(5), 1361; DOI:10.5012/bkcs.2013.34.5.1361

12. Frisch M J, Trucks G W, Schlegel H B, Scuseria G E, Robb M A, Cheeseman J R, Zakrzewski V G, Montgomery J A, Stratmann R E, Burant J C, Dapprich S, Millam J M, Daniels A D, Kudin K N, Strain M C, Farkas O, Tomasi J, Barone V, Cossi M, Cammi R, Mennucci B, Pomelli C, Adamo C, Clifford S, Ochterski J, Petersson G A, Ayala P Y, Cui Q K, Morokuma D K, Malick Stefanov B B, Liu G, Liashenko A, Piskorz P, Komaromi I, Gomperts R, Martin R L,Fox D J, Keith T, Al-Laham M A, Peng C Y, Nanayakkara A, Gonzalez C, Challacombe M, Gill P M W, Johnson B, Chen W, Wong M W, Andres J L,Gonzalez C, Head-Gordon M, Replogle E S and Pople J A, Gaussian 03, Gaussian Inc., Pittsburgh, PA, 2003.

13. Lee C, Yang W and Parr R G, Phys Rev B., 1988, 37(2), 785.

14. Becke A D, J Chem Phys., 1993, 98(7), 5648; DOI:10.1063/1.464913

15. Zhang J-Y, Du H -C, Wang F, Gong X-D and Huang Y-S, J Phys Chem A, 2011, 115(24), 6617-6621; DOI:10.1021/jp1118822

16. Hill T L, Introduction to Statistic Thermodynamics, Addison-Wesley, New York, 1960.

17. Parr R G and Yang W, 1989 Density Functional Theory of Atom and Molecules (Oxford: Oxford University Press).

18. Seminario J M and Politzer P, 1995 Modern density functional theory; A tool for chemistry (Amsterdam: Elsevier).

19. Xu X J, Xiao H M, Gong X D, Ju X H and Chen Z X, J Phys Chem A, 2005, 109(49), 11268-11274; DOI:10.1021/jp040472q

20. Ghule V, Jadhav P, Patil R, Radhakrishnan S and Soman T, J Phys Chem A, 2010, 114(1), 498-503; DOI:10.1021/jp9071839 
21. Dean J A, LANGE'S Handbook of Chemistry, $15^{\text {th }}$ Ed., McGraw-Hill., New York, 1999.

22. Wilcox C F, Zhang Y X and Bauer S H, J Mol Struct, Theochem., 2000, 528(1-3), 95109; DOI:10.1016/S0166-1280(99)00475-3

23. Curtiss L A, Raghavachari K, Redfem P C and Pople J A, J Chem Phys, 1997, 106, 1063-1079; DOI:10.1063/1.473182

24. Atkins P W, Physical Chemistry, $2^{\text {nd }}$ Ed., Oxford University Press, Oxford, 1982.

25. Politzer P, Ma Y, Lane P and Concha M C, Int J Quantum Chem., 2005, 105(4), 341347; DOI:10.1002/qua.20709

26. Politzer P, Murray J S, Grice M E, Desalvo M and Miller E, Mol Phys., 1997, 91(5), 923-928; DOI:10.1080/002689797171030

27. Byrd E F C and Rice B M, J Phys Chem A, 2006, 110(3), 1005-1013;

DOI:10.1021/jp0536192

28. Bulat F A, Toro-Labbe A, Brinck T, Murray J S and Politzer P, J Mol Model., 2010, 16(11), 1679-1691; DOI:10.1007/s00894-010-0692-x

29. Jaidann M, Roy S, Abou-Rachid H and Lussier L S, J Hazard Mater., 2010, 176(1-3), 165-173; DOI:10.1016/j.jhazmat.2009.10.132

30. Wang Y, Qi C, Song J-W, Zhao X-Q, Sun C-H and Pang S P, J Mol Model., 2013, 19(3), 1079-1087; DOI:10.1007/s00894-012-1647-1

31. Kamlet M J and Jacobs S J, J Chem Phys., 1968, 48(1), 23; DOI:10.1063/1.1667908

32. Chi W J, Li L L, Li B T and Wu H S, J Mol Model., 2012, 18(8), 3695-3704; DOI:10.1007/s00894-012-1367-6

33. Politzer P, Martinez J, Murray J S, Concha M C and Toro-Labbé A, Mol Phys., 2009, 107(19), 2095-2101; DOI:10.1080/00268970903156306

34. Politzer P and Murray J S, J Mol Struct., 1996, 376(1-3), 419-424;

DOI:10.1016/0022-2860(95)09066-5

35. Qiu L, Gong X D and Xiao H M, Chin J Chem., 2008, 26(12), 2165-2172;

DOI:10.1002/cjoc.200890386

36. Blanksby S J and Ellison G B, Acc Chem Res., 2003, 36(4), 255-263;

DOI:10.1021/ar020230d

37. Fukui K, Theory of Orientation and Stereoselection, Reactivity and Structure, Concepts in Organic Chemistry, Springer, Berlin, 1975.

38. Abou-Rachid H, Song Y, Hu A, Dudiy S, Zybin S V and Goddard W A, J Phys Chem $A, 2008$, 112(46), 11914-11920; DOI:10.1021/jp8026644

39. Talawar M B, Sivabalan R, Mukundan T, Muthurajan H, Sikder A K, Gandhe B R and Rao A S, J Hazard Mater., 2009, 161(2-3), 589-607;

DOI:10.1016/j.jhazmat.2008.04.011

40. Sikder A K and Sikder N, J Hazard Mater., 2004, 112(1-2), 1-15;

DOI:10.1016/j.jhazmat.2004.04.003

41. Murray J S, Concha M C and Politzer P, Mol Phys., 2009, 107(1), 89-97;

DOI:10.1080/00268970902744375

42. Xiao H-M, Fan J-F, Gu Z-M and Dong H S, Chem Phys., 1998, 226(1-2), 15-24; DOI:10.1016/S0301-0104(97)00288-7

43. Xiao H M and Chen Z X, The Modern Theory for Tetrazole Chemistry, $1^{\text {st }}$ Ed., Science Press, Beijing, 2000.

44. Wang G X, Gong X D, Liu Y and Xiao H M, Int J Quantum Chem., 2010, 110(9), 1691-1701; DOI:10.1002/qua.22306

45. Chung G, Schmidt M W and Gordon M S, J Phys Chem A, 2000, 104, 5647-5650; DOI:10.1021/jp0004361 